\title{
Conditions for the generation of beta band activity in Parkinson's disease
} Alejo J Nevado Holgado*1, John Terry ${ }^{2}$ and Rafal Bogacz ${ }^{1}$

\author{
Address: ${ }^{1}$ Department of Computer Science, University of Bristol, Bristol, UK and ${ }^{2}$ Department of Engineering Mathematics, University of Bristol, \\ Bristol, UK \\ Email: Alejo J Nevado Holgado* - nevado@cs.bris.ac.uk \\ * Corresponding author
}

from Eighteenth Annual Computational Neuroscience Meeting: CNS*2009

Berlin, Germany. 18-23 July 2009

Published: 13 July 2009

BMC Neuroscience 2009, I0(Suppl I):P247 doi:I0.I I86/I47|-2202-I0-SI-P247

This abstract is available from: http://www.biomedcentral.com//47/-2202/I0/SI/P247

(C) 2009 Holgado et al; licensee BioMed Central Ltd.

\section{Background}

The basal ganglia plays a key role in motor control, and its dysfunction is associated with various neurological disorders including Parkinson's disease. The symptoms of Parkinson's disease include bradykinesia, characterized by a general slowing of movement execution. The advance of bradykinesia is highly correlated with the presence of abnormal oscillations within basal ganglia in the beta band frequency [1]. Some evidence suggests the oscillations observed in the basal ganglia originate from the network comprised of two nuclei: subthalamic nucleus (STN) and globus pallidus pars externa (GPe) [2], while other authors attribute their source to the entire corticobasal-ganglia-thalamic circuit [3]. In this work, we attempt to address this question of the origin of beta band oscillations.

\section{Methods}

In the present study, we develop a computational model of the STN-GPe network based upon anatomical and electrophysiological studies. We take the parameters of the model directly from experimental studies (where possible), or estimate them by fitting the output of the model to observations from several neurophysiological studies [4]. We then model the advance of Parkinson's disease by increasing weights of certain synaptic connections in the model in accordance with the experimental literature [5].

\section{Results and discussion}

Simulations of the model demonstrate that as the parameters were changed to values corresponding to Parkinson's disease, the model started to produce oscillations with a frequency close to $30 \mathrm{~Hz}$ (i.e. within the beta band). To establish analytically the occurrence of these oscillations, we considered appropriate reductions of the model. The analysis of the reduced models allowed us to identify a simple set of necessary conditions on model parameters, which guarantees the existence of oscillatory behavior in the beta band frequency. To check the validity of these conditions in the reduced and the full model, both models were simulated in a wide range of parameters. We observed that in both the reduced and full model, our analytical conditions defined very closely the boundary of the region in parameter space in which the models produced oscillations in the beta band.

Our simulations and analysis demonstrate that the beta band oscillations observed in Parkinson's disease can arise due to intrinsic properties of the STN-GPe circuit, rather than as a result of an external pacemaker from another neural region (i.e. cortex or striatum). Furthermore, we identified conditions the parameters of the network needed to satisfy to produce the oscillations. Most significantly, these conditions describe changes in parameters that are consistent with those expected as a result of the development of Parkinon's disease, and predict manipulations that could inhibit the pathological oscillations. 


\section{Acknowledgements}

The PhD scholarship of Alejo Nevado is funded by Fundación Caja Madrid, Madrid, Spain.

\section{References}

I. Boraud T, Brown P, Goldberg JA, Graybiel AM, Magill PJ: Oscillations in the basal ganglia: The good, the bad, and the unexpected. The Basal Ganglia VIII 2005: I-24.

2. Plenz D, Kital ST: $\mathbf{A}$ basal ganglia pacemaker formed by the subthalamic nucleus and external globus pallidus. Nature 1999, 400:677-682.

3. Leblois A, Boraud T, Meissner W, Berman H, Hansel D: Competition between feedback loops underlies normal and pathological dynamics in the basal ganglia. J Neurosci 2006, 26:3567-3583.

4. Kita H, Tachibana $Y$, Nambu A, Chiken S: Balance of monosynaptic excitatory and disynaptic inhibitory responses of the globus pallidus induced after stimulation of the subthalamic nucleus in the monkey. J Neurosci 2005, 25:86II-8619.

5. Shen K, Johnson SW: Dopamine depletion alters responses to glutamate and GABA in the rat subthalamic nucleus. Neuroreport 2005, 16:17I-174.

Publish with Bio Med Central and every scientist can read your work free of charge

"BioMed Central will be the most significant development for disseminating the results of biomedical research in our lifetime."

Sir Paul Nurse, Cancer Research UK

Your research papers will be:

- available free of charge to the entire biomedical community

- peer reviewed and published immediately upon acceptance

- cited in PubMed and archived on PubMed Central

- yours - you keep the copyright

Submit your manuscript here:

http://www.biomedcentral.com/info/publishing_adv.asp 